\title{
Which Drinking Water Disinfection Process Generates the Least Toxic DBP Mixture: Chlorination, Chloramination, Ozonation, or Chlorine Dioxide Treatment?
}

\section{Xiangru Zhang* Hong Kong SAR, China \\ Complexity and Unknowns of Disinfection Byproducts (DBPs) in Drinking Waters}

JCEE editorial board member, Department of Civil and Environmental Engineering, The Hong Kong University of Science and Technology, Clear Water Bay, Kowloon,

Chlorine, chloramines, chlorine dioxide, and ozone are widely used drinking water disinfectants. The use of these disinfectants affords great success in eliminating harmful microorganisms and acute waterborne diseases, but in the disinfection process, they may react with Natural Organic Matter (NOM), bromide, and iodide in source waters to produce DBPs.

NOM in natural waters mainly originates from the decomposition of plants. It consists of a wide variety of complex organic compounds with molecular weights ranging from hundreds to hundreds of thousands of $\mathrm{Da}$ [1]. The complexity of NOM determines a higher magnitude of complexity of the reaction products from disinfectants and NOM with/without bromide and iodide. Since Rook [2] first found trihalomethanes as DBPs in finished drinking water in 1974, numerous DBPs have been identified in real or simulated drinking waters. Commonly known DBPs include trihalomethanes, haloacetic acids, haloacetonitriles, haloketones, cyanogen halides, chloropicrin, chloral hydrate, N-nitrosodimethylamine, bromate, and chlorite. Richardson [3] compiled a review on drinking water DBPs formed from using four major disinfectants, in which she listed about 600 DBPs that were identified by gas chromatography/mass spectrometry (GC/MS). Of the 600 DBPs, some are commonly known DBPs and occur at low- $\mu \mathrm{g} / \mathrm{L}$ levels, some occur at sub- $\mu \mathrm{g} / \mathrm{L}$ or ng/L levels, and some may still not be quantifiable [4]. The non-quantifiable DBPs are because of no corresponding standard compounds for calibration or their concentrations below detection limits. In addition, there are a countless number of unidentified/unknown DBPs.

A collective parameter for all the organic halogenated DBPs is total organic halogen (TOX). Only a fraction of TOX formed during disinfection has been chemically identified or even well characterized $[5,6]$. By simulating a typical drinking water disinfection condition, Zhang et al. [7] demonstrated that the percentages of total organic chlorine (TOCl) that could be represented by the commonly known chlorinated DBPs in the chlorine, chlorine dioxide, and chloramine treated samples were 50,31 , and $17 \%$, respectively; the percentages of total organic bromine (TOBr) that could be represented by the commonly known brominated DBPs in the chlorine, chlorine dioxide, chloramine, and ozone treated samples were $60,26,14$, and $8.2 \%$, respectively. The uncounted parts of TOX, TOCl and TOBr are mainly ascribed to unknown/unidentified DBPs in drinking waters, which may exist due to limitations of GC/MS because GC/MS is not amenable to identification of highly polar compounds, and compounds with molecular weights of more than $650 \mathrm{Da}$ [8]. Recently, novel precursor ion scan methods using ultra performance liquid chromatography/ electrospray ionization-triple quadrupole mass spectrometry have been developed for fast selective detection of polar chloro-/bromo-/ iodo-DBPs in drinking waters [9-12].

\section{Status Quo and Existing Problems of Toxicologic Studies on DBPs in Drinking Waters}

Although DBP levels in most finished drinking waters are very low, "the large absolute amount of water (about 50,000 liters) ingested by an individual over a lifetime means that human exposure to chemical contaminants may be significant [3]". Epidemiological studies suggest that human consumption of chlorinated drinking water is somewhat associated with increased spontaneous abortions, stillbirth, birth defects, bladder cancer, and rectal cancer [13]. Some DBPs have been regulated in Stage I of the Disinfectants/Disinfection By-Products (D/ DBP) Rule by the U.S. Environmental Protection Agency [14].

A vast majority of laboratory-based toxicologic studies have been conducted with individual DBPs [15]. Richardson et al. [16] reviewed 30 years of research on the occurrence, genotoxicity, and carcinogenicity of 85 DBPs. A systematic assessment of individual DBPs for genotoxicity has been performed for 60 DBPs for DNA damage in mammalian cells and 16 for mutagenicity in Salmonella. The results show that eight of them have some or all of the toxicologic characteristics of human carcinogens, and 29 of them are genotoxic; brominated DBPs are both more genotoxic and carcinogenic than their chlorinated analogues, and iodinated DBPs were the most genotoxic of all.

Most toxicologic studies on individual DBPs are conducted with bacterial or mammalian cell assays, i.e., the cytotoxicity and mutagenicity assays using Salmonella typhimurium strain TA100 [17], or the cytotoxicity and genotoxicity assays using Chinese hamster ovary cells [18]. Both types of assays have been used to quantitatively compare cytotoxicity, mutagenicity or genotoxicity of known individual DBPs. In cytotoxicity assays, for instance, the DBP concentration that induces 50\% repression of growth is LC50. With LC50 values, the cytotoxicity rank order of individual DBPs can be assigned. Although toxicologic results of individual DBPs can be indicative of mechanisms of health effects, they cannot be directly linked to the toxicity of a whole DBP mixture. This is because: (a) for the individual DBPs that have been performed with the bacterial or mammalian cell assays, the concentrations that induce the cytotoxicity, mutagenicity or genotoxicity are around 4-6 orders of magnitude higher than their actual concentrations in drinking water; (b) the

*Corresponding author: Xiangru Zhang, JCEE editorial board member Department of Civil and Environmental Engineering, The Hong Kong University of Science and Technology, Clear Water Bay, Kowloon, Hong Kong SAR, China, E-mail: xiangru@ust.hk

Received March 24, 2012; Accepted March 26, 2012; Published March 28, 2012 Citation: Zhang X (2012) Which Drinking Water Disinfection Process Generates the Least Toxic DBP Mixture: Chlorination, Chloramination, Ozonation, or Chlorine Dioxide Treatment? J Civil Environment Engg 2:e105. doi:10.4172/2165784X.1000e105

Copyright: () 2012 Zhang X. This is an open-access article distributed under the terms of the Creative Commons Attribution License, which permits unrestricted use, distribution, and reproduction in any medium, provided the original author and source are credited. 
number of DBPs in drinking water is countless and most of them are unknown, unidentified or non-quantifiable, and thus it is prohibitive and unlikely to achieve the occurrence and toxicologic data of all individual DBPs; (c) even if the occurrence and toxicologic data of all individual DBPs are achievable, the toxicity of the whole DBP mixture may still not be achievable owing to potential interactions among the DBPs. These interactions can be addition, synergy, and antagonism. Synergy (or antagonism) is a phenomenon where two or more agents in combination have an overall effect which is greater (or less) than the sum of their individual effects. Accordingly, evaluation of the toxicity of each individual DBP alone is insufficient for understanding the biological effects of the whole DBP mixture. Importance of estimating the overall toxicity of DBP mixtures has been increasingly recognized in most recent years $[19,20]$.

Despite numerous toxicologic reports on individual DBPs, significantly fewer investigations have been done on DBP mixtures. Only a couple of studies have examined the cytotoxicity and mutagenicity of drinking water extracts in Salmonella or mammalian-cell assays. A disinfected drinking water sample itself seems to be an ideal DBP mixture, but it cannot be used directly for the bacterial or mammaliancell assay because either the bacterial or the mammalian-cell assay is not sensitive enough. To perform the bacterial or mammalian-cell assay of a drinking water DBP mixture, it is most critical to concentrate the drinking water sample.

There are two procedures for concentrating a drinking water sample for the bioassays. (a) Solid phase extraction [13,21,22]: 20-200 $\mathrm{L}$ of disinfected drinking waters (with source water DOC of 1.6-9.0 $\mathrm{mg} / \mathrm{L}$ as $\mathrm{C}$ ) $\rightarrow$ acidified to $\mathrm{pH} 2 \rightarrow$ filtrated by XAD-2 / CHP20P resin or by $\mathrm{C}_{18}$ / CSP- 800 cartridge $\rightarrow$ the resin or cartridge eluted with methanol / acetonitrile / dichloromethane / acetone / ethyl acetate / DMSO $\rightarrow$ the eluates evaporated to dryness $\rightarrow$ dissolved in $0.8-2.0 \mathrm{~mL}$ DMSO. The samples were concentrated by 10,000-200,000 times. (b) Liquid phase extraction [17,18]: $70 \mathrm{~mL}$ of a simulated chlorinated water sample (with source water DOC of $108 \mathrm{mg} / \mathrm{L}$ as C) $\rightarrow$ lyophilized to dryness $\rightarrow$ extracted with ethyl acetate $\rightarrow$ the organic layer evaporated to dryness $\rightarrow$ dissolved in $200 \mu \mathrm{L}$ DMSO. The highly dosed simulated sample was concentrated by 350 times. Compared to the typical DOC level in source water, this sample was concentrated by $\sim 10,000$ times.

For either the solid or liquid phase extraction of a typical drinking water sample or a highly dosed drinking water sample, concentration of organic DBPs up to 10,000-200,000 times and removal of dissolved inorganic salts are the prerequisites for the bacterial or mammalian-cell assays. In the extraction procedure, apart from the tedious and timeconsuming steps involved, a major problem is that part or all of certain specific types of DBPs may be lost. For the solid phase extraction, all inorganic DBPs (such as bromate in ozonated water and chlorite in chlorine dioxide treated water) and some polar/highly polar organic DBPs may not be adsorbed on the resin/cartridge, some organic DBPs strongly adsorbed on the resin/cartridge may not be desorbed during eluting with the organic solvent(s), and all volatile organic DBPs are lost during solvent evaporation to dryness. For the liquid phase extraction, a similar problem may occur. Therefore, the extracts involve significant losses in DBP species and levels, and thus cannot accurately reflect the toxicity of drinking water DBP mixtures.

\section{A New Approach Needed to Evaluate the Toxicity of Drinking Water DBP Mixtures}

Chlorine is the most widely used disinfectant. Chlorination generates relatively high levels of chlorinated/brominated organic
DBPs [7] including chloro-/bromo- trihalomethanes and haloacetic acids, 9 of which have been regulated in Stage I of the D/DBP Rule [14]. To reduce the formation of chlorinated/brominated organic DBPs, some drinking water utilities have switched to alternative disinfectants such as ozone, chlorine dioxide, and chloramine, however, other DBPs are formed. For instances, ozonation and chlorine dioxide treatment generate bromate and chlorite, respectively, both of which have also been regulated in Stage I of the D/DBP Rule [14]; chloramination generates relatively high levels of iodo-DBPs $[6,11,23]$. Only a few early studies examined the Salmonella mutagenicity of solid phase extraction extracts of drinking waters prepared with alternative disinfectants, and the results showed that drinking water with alternative disinfectants was less mutagenic than chlorinated drinking water [16]. However, as aforementioned, the organic extracts by solid phase extraction involve significant losses in DBP species and levels (e.g. they completely exclude bromate and chlorite), and thus cannot adequately represent the toxicity of the DBP mixtures of drinking waters.

Now that the solid or liquid phase extraction may cause significant DBP losses, a new approach to evaluating the toxicity of drinking water DBP mixtures should involve a better procedure for concentrating all types of DBPs, including organic and inorganic, and volatile and polar ones. Also, since the bacterial or the mammalian-cell assay is not sensitive enough, a new approach should entail a more sensitive bioassay species to the DBPs mixtures. It is expected that, with the new approach, the long-lasting issue in drinking water disinfection-which disinfection process generates the least toxic DBP mixture, chlorination, chloramination, ozonation, or chlorine dioxide treatment?-can be resolved.

\section{References}

1. Snoeyink VL, Jenkins D (1980) Water Chemistry; John Wiley \& Sons: New York.

2. Rook JJ (1974) Formation of haloforms during chlorination of natural waters. Water Treat Exam. 23: 234-243.

3. Richardson SD, Postigo C (1998) Drinking water disinfection by-products. Ear Environ \& Sci 19: 1-45

4. Xie $Y$ (2003) Disinfection byproducts in drinking water: formation, analysis, and control. CRC Press - 176

5. Singer PC, Chang SD (1989) Correlations between trihalomethanes and total organic halides formed during water treatment. J Am Water Works Assoc 81 61-65

6. Krasner SW, Weinberg HS, Richardson SD, Pastor SJ, Chinn R, et al. (2006) Occurrence of a new generation of disinfection byproducts. Environ Sci Technol 40: 7175-7185

7. Zhang X, Echigo S, Minear RA, Plewa MJ (2000) Characterization and comparison of disinfection by-products of four major disinfectants. ACS Symposium Series 761: 299-314.

8. Zhang X, Minear RA (2002) Characterization of high molecular weigh Disinfection Byproducts resulting from chlorination of aquatic humic substances. Environ Sci Technol 36: 4033-4038.

9. Zhang X, Minear RA, Barrett SE (2005) Characterization of high molecula weight disinfection byproducts from chlorination of humic substances with/ without coagulation pretreatment using UF-SEC-ESI-MS/MS. Environ Sci Technol 39: 963-972.

10. Zhang X, Talley JW, Boggess B, Ding G, Birdsell D (2008) Fast selective detection of polar brominated disinfection byproducts in drinking water using precursor ion scans. Environ Sci Technol 42: 6598-6603.

11. Ding G, Zhang X (2009) A picture of polar iodinated disinfection byproduct in drinking water by (UPLC/) ESI-tqMS. Environ Sci Technol 43: 9287-9293.

12. Zhai $H$, Zhang $X(2011)$ Formation and decomposition of new and unknown polar brominated disinfection byproducts during chlorination. Environ Sci Technol 45: 2194-2201. 
Citation: Zhang X (2012) Which Drinking Water Disinfection Process Generates the Least Toxic DBP Mixture: Chlorination, Chloramination, Ozonation, or Chlorine Dioxide Treatment? J Civil Environment Engg 2:e105. doi:10.4172/2165-784X.1000e105

13. Monarca S, Zani C, Richardson SD, Thruston Jr AD, Moretti M, et al. (2004) A new approach to evaluating the toxicity and genotoxicity of disinfected drinking water. Water Res 38: 3809-3819.

14. U.S. Environmental Protection Agency (1998) National Primary Drinking Water Regulations: Disinfectants and Disinfection Byproducts. Fed. Reg. 63: 69389.

15. Simmons JE, Teuschler LK, Gennings C, Speth TF, Richardson SD, et al. (2004) Component-based and whole-mixture techniques for addressing the toxicity of drinking-water disinfection by-product mixtures. J Toxicol Environ Health Part A 67: 741-754.

16. Richardson SD, Plewa MJ, Wagner ED, Schoeny R, DeMarini DM (2007) Occurrence, genotoxicity, and carcinogenicity of regulated and emerging disinfection by-products in drinking water: A review and roadmap for research. Mutat Res 636: 178-242.

17. Kargalioglu YK, McMillan BJ, Minear RA, Plewa MJ (2000) A new assessment of the cytotoxicity and genotoxicity of drinking water disinfection byproducts Natural Organic Matter and Disinfection By-products, Characterization and Control in Drinking Water, Barrett SE, Kransner SW, Amy GL (Eds.) American Chemical Society: Washington, DC 39: 198-201.
18. Liviac D, Wagner ED, Mitch WA, Altonji MJ, Plewa MJ (2010) Genotoxicity of water concentrates from recreational pools after various disinfection methods. Environ Sci Technol 44: 3527-3532.

19. Echigo S, Itoh S, Natsui T, Araki T, Ando R (2004) Contribution of brominated organic disinfection by-products to the mutagenicity of drinking water. Water Sci Technol 50: 321-328.

20. Itoh S, Gordon BA, Callan P, Bartram J (2011) Regulations and perspectives on disinfection by-products: importance of estimating overall toxicity. J Water Supply Res Technol 60: 261-274.

21. Lerda DE, Prosperi CH (1996) Water mutagenicity and toxicology in Rio Tercero (Cordoba, Argentina). Water Res 30: 819-824.

22. Buschini A, Giordani F, Pellacani C, Rossi C, Poli P (2008) Cytotoxic and genotoxic potential of drinking water: a comparison between two different concentration methods. Water Res 42: 1999-2006.

23. Bichsel Y, Von Gunten U (1999) Oxidation of iodide and hypoiodous acid in the disinfection of natural waters. Environ Sci Technol 33: 4040-4045 